\title{
Ontological Security in Nursing Homes for Older Persons - Person-Centred Care is the Power of Balance
}

\author{
Inger James ${ }^{*}, 1$, Rebecka Ardeman-Merten ${ }^{2}$ and Annica Kihlgren ${ }^{1}$ \\ ${ }^{I}$ School of Health and Medical Sciences, Örebro University, Örebro, Sweden \\ ${ }^{2}$ Örebro Municipallity, Healthcare and Social Services, Örebro, Sweden
}

\begin{abstract}
Introduction: The Swedish national guidelines for elderly care describe how older persons should be able to trust that their care is permeated with security. Different theoretical perspectives can be found that describe what creates security. Many studies have been done about security. However, few studies have explicitly asked older persons what security in nursing homes means to them.

Aim: The aim of the study was to describe how older persons in nursing homes talked and reflected about security in their daily lives.

Method: Nine older persons were interviewed in, in-depth interviews one to three times and the resulting data was analysed using content analysis.

Results: The older persons adapted to having their own needs and those of the other older persons met and to the staff routines which created a sense of security. At the same time, they longed for security in which they could trust themselves and create their own daily life. Further to have a sense of belonging and of being liked for created an internal, interpersonal and external security. This can be linked to an ontological security which means having a sense of confidence in the continuity of self-identity and order in events, a being in the world.

Conclusion: Person-centred instead of institution- centred care can provide the balance of power that allows the older person to obtain ontological security in which the staff's ability to create a relationship with the older persons becomes crucial.
\end{abstract}

Keywords: Adaptation, elderly care, nursing home, ontological security, person-centred care, relationship.

\section{INTRODUCTION}

Shortcomings exist in the care of older persons in many parts of the world [1]. To overcome the shortcomings in Swedish elderly care, national guidelines for elderly care were introduced in Sweden in 2011; in the guidelines older persons are assured of the right to have a dignified life, wellbeing and everyday life organized in a meaningful way. The guidelines also address issues of security, one focus in discussions of elderly care; the guidelines describe how older persons should be able to trust that their care is permeated with security $[2,3]$.

Different theoretical perspectives can be found that describe what creates security. Kaufmann describes security as a human need, which is manifested in a need for protection, internal balance, and orientation [4]. Maslow [5] states that if physiological and psychological needs, which are prerequisites for basic security, are met in childhood, this can make people strong when facing threatening situations later in life. According to Bowlby's attachment theory [6], basic security can evolve if the parents are linked to and keep close to the

*Address correspondence to this author at the School of Health and Medical Sciences, Örebro University, SE - 70182 Örebro, Sweden; Tel: +46 1930 10 95, + 46193030 00; Fax: +46 193036 01; E-mail: inger.james@oru.se child. Crittenden [7] says that security at one age does not predict security at later ages. People have their own strategies for creating protection, where sensitive relation-ships and safe environments can promote a sense of security. Giddens $[8,9]$ argues that feeling that persons and things are trustworthy becomes fundamental to the ontological security. Routines and habits, in other words, lifestyle, also create an external order which can lead to an emotional security.

Older persons living in ordinary homes and receiving home care describe security as recognizing themselves in their habits and routines and having faith in themselves [10]. Security also means not being afraid of being alone, having control over their lives and being able to trust their own bodies despite health problems [11]. They also described having confidence in their environment and understanding what is going on [10], having a sense of well-being and living life as usual as being important [11]. Security also meant being assured of receiving help from the staff in their home and having emotional engagement and help from someone they know well such as staff, children and/or grandchildren [10]. Many older persons live on the "threshold" of insecurity where every day routines and habits are failing because they can be difficult to maintain or managed by themselves or with the help from family members $[12,13]$. Older persons can move to nursing homes to obtain security and have access to the help they need [14-17] to secure the insecure 
body [14]. Nursing homes are also described as a safe place where people can live with others [16]. There stable staffing contributes to the older persons' sense of security [18]. However, Timonen and O'Dwyer [19] revealed that older persons in nursing homes may have more unmet needs that can be linked to Maslow's hierarchy of needs where security is described as a need. Moving to a nursing home can mean losses and limitations [19] and an institution-centred care [20]. From et al. [13] showed in a study of older person's view of health care, that when older persons are dependent on community care, feeling healthy is one way to obtain security in daily life. Another way for them to have security is by having routines in their daily life [21]. However, few studies have explicitly asked older persons what security in nursing homes means to them. Since older persons' right to security is being stressed $[2,3]$, it becomes important to ask older persons in nursing homes what security means for them. The aim of the study was to describe how older persons talked and reflected about security in their daily lives.

\section{METHOD}

The study has a descriptive design with a qualitative approach.

\section{Context and Sampling}

This study is part of a larger interdisciplinary action research project conducted in 2011 within a municipality in central Sweden. The project's aim was to investigate how a meaningful daily life could be developed for older persons within nursing homes and home care. For the main study, six nursing homes and six home care units were randomly selected from a list of all nursing homes and home care units in the municipality [22]. This study focuses only on nursing homes. Two of those chosen had received good reviews; two had received moderately good reviews; and two, less favourable reviews from a completed user survey [22, 23]. Five nursing homes agreed to participate in the main study. Inclusion criteria were older persons who were able to express themselves verbally, understand the meaning of an interview and agree to participate. Persons with dementia or cognitive impairments were not excluded. The managers in each nursing home did an aptitude sample of older persons who could participate in an interview. A staff member asked the selected older persons verbally if they were willing to participate in an interview. If any older person did not want to be interviewed, the next person was consulted. In total, 30 older persons were selected for an interview. Written information was then given to the older person about the main purpose of the study and informed consent forms were collected. During the interviews in the main study, the older persons described security as something that was important to experiencing meaningfulness. In line with action research, it became important to conduct further interviews with a focus on older person's reflections and stories about security, which are reported in this study. The unit manager at each nursing home told the author who had previously consented to participate, and they were asked to participate in a follow-up interview. Nine persons who were 83 to 100 years of age $(\mathrm{M}=92$ years), participated. They had lived in their nursing home between one to eight years ( $\mathrm{M}=3.1$ years). Three older persons were interviewed three times, three were interviewed twice and three person, interviewed once, for a total of 18 interviews.

\section{Ethical Considerations}

Several ethical deliberations were conducted before we entered the field. The inclusion of older persons with potential cognitive impairment might be considered unethical. However, Szala-Meneok [24] argues that in research, vulnerable older persons require special consideration but should not be excluded because of failing health, as they have the right to influence the care that they are dependent on $[2,24]$. The older persons were informed about the purpose of the study, how the results would be introduced and that the study was voluntary. They could withdraw their participation at any time without giving any explanation. They gave their written informed consent prior to the interviews. Ethical approval was granted by the Regional Research Ethical Committee (registration number 2011/009).

\section{Data Collection}

Repeated, in-depth interviews [25] were conducted by the second author to capture more profound feelings, reflections and descriptions of security. The older person was free to choose the place for the interviews and they took place in the older person's apartment. The interviews started with a general question: "Can you please tell me what security means to you?" Follow-up questions might be, for instance, "What do you think about that?" or "How do you feel about that?" The interviews were conducted as conversations in which the participants were encouraged to talk as freely as possible. However the older persons could have difficulties to express themselves and keep the "thread" during conversation. To handle this the second author waited for the older persons, followed them into other stories and then returned the conversation back to security. Repeat what the older person had been said about security or put the questions in a simpler way. When the older persons also became tired the author then stop the conversation went out of the room and let the person rest for a while or returned another day.

After the first interview, the author read the transcriptions and made a compilation of what the persons had been said. Before the second and third interview started, the older person in some cases read the whole or part of the compilation or the second author read the compilation out loud to the older person to give the person a chance to reflect upon what had been said. This was also done to create a richer conversation during the interviews $[25,26]$. In the second and third interviews, the older persons were asked follow-up questions such as "What do you think when you read/hear what we have been talking about?" "What have you been thinking about it all since the last time we met?" The intervals between the repeated interviews varied from one week to one month. Each interview lasted from 25 to 60 minutes and all were recorded on an MP3 player. An experienced secretary transcribed all interviews verbatim. 


\section{Data Analysis}

The transcriptions of the 18 interviews were subjected to manifest and latent content analysis, as described by Graneheim and Lundman [27]. In the first part of the analysis, the authors read through the transcriptions several times to acquire a general sense of the whole. Then meaning units relevant to the aim of the study were identified, condensed and coded. Focus was on the manifest content, i.e., what was said by the older persons. The codes were then compared to each other and checked for differences and similarities to verify their consistence. An abstraction was done by arranging the codes with similar meaning into subcategories. In the next step, the subcategories were checked for differences and similarities. Subcategories with similar meaning were sorted into categories. Thereafter, the theme was created and can be seen as the expression of the latent content in the manifest part of the text. Throughout the analysis the authors critically scrutinized and repeatedly discussed the results to ensure trustworthiness and the best form of presentation.

\section{RESULTS}

The result begins with the theme which describes the older person's stories and reflections of what security means for them overall. Thereafter the categories and subcategories will be presented; there each category begins with a summary (see Table 1).

The older persons did not distinguished between the different types of professionals working at the nursing home and referred to them as "staff" so the term "staff" has been used in describing the results. Hesitation and unnecessary words are marked with (...) and brackets [] indicate the author's comments.

\section{Theme}

The older persons talked about and reflected on an internal, interpersonal and external sense of security. In their stories and reflections they described what security was and what it was not and showed a longing for what security could be; On one hand, the older persons adapted to having their own needs and those of the other older persons met and to the staff routines and this formed a sense of reciprocity that created a sense of security. On the other hand they longed for security where they could trust themselves and create their own daily life, to have a sense of belonging and of being liked.

\section{Internal Security - To Trust Oneself}

For the older person, being able to manage on their own meant they could trust themselves, which creates an internal security. Since they had become more dependent, they had adapted to their increased needs in order to obtain an internal security. They had a longing to be free and to make their own choices and create their own daily life.

\section{To Manage on One's Own}

The older person described security as being able to manage on one's own in everyday life as much and for as long as possible. This meant having the ability to manage their personal health and hygiene, to get dressed and undressed, to eat unaided and to be able to walk and move about. One older person said: "Yes it is, of course, that I can take care of myself. I cannot imagine become a package".

They also said that no matter how much help they needed, it was still important to be able to perform certain tasks and routines by themselves, like paying bills: "And I pay my rent myself". They reflected that knowing what help they needed in everyday life could provide security because they would know what kind of help they could ask the staff for. This was a way to be able to manage on their own as long as possible.

\section{To Adapt to One's Own Needs}

The older persons spoke about how their health had deteriorated and they had had no other choice then to move out of their ordinary home into a nursing home: "Then my husband died so I was alone. I became worse and then I was moved. It happens - you may follow".

Life was different than before and they had moved from being more or less independent and handling their personal care to become increasingly dependent. Dependence could mean needing help to move, to get out of bed and to go to the toilet. An older person said: "I need help with everything". The older persons expressed that they had no choice they had to adapt to their own needs in order to feel secure.

\section{To be Able to Choose}

Some of the older people described security as being able to be free and to shape their daily lives based on their own needs and desires. They wanted, for example, to be able to choose with whom they wanted to be and spend their time. They also said that security could be being able to choose to

Table 1. Summary of subcategories and categories of internal, interpersonal and external sense of security. The theme described what security means for the older persons in this study.

\begin{tabular}{|c|l|l|l|}
\hline \multirow{2}{*}{ Theme } & \multicolumn{2}{|c|}{$\begin{array}{l}\text { On one hand, the older persons adapted to having their own needs and those of the other older persons met and to the staff routines and } \\
\text { this formed a sense of reciprocity that created a sense of security. On the other hand they longed for security where they could trust } \\
\text { themselves and create their own daily life, to have a sense of belonging and of being liked. }\end{array}$} \\
\hline Category & \multicolumn{1}{|c|}{$\begin{array}{c}\text { Internal Security - } \\
\text { To Trust Oneself }\end{array}$} & \multicolumn{1}{|c|}{$\begin{array}{c}\text { Interpersonal Security - } \\
\text { To Interact with Others }\end{array}$} & $\begin{array}{c}\text { External Security - To Obtain } \\
\text { Protection }\end{array}$ \\
\hline Sub-category & $\begin{array}{l}- \text { To manage on one's own } \\
- \text { To adapt to one's own needs } \\
- \text { To be able to choose }\end{array}$ & $\begin{array}{l}\text { - To adapt to others and to the staff's routines } \\
- \text { To recognizing oneself in others } \\
- \text { To sense reciprocity } \\
- \text { To long for coherence and affinity } \\
- \text { To long for to be liked }\end{array}$ & - To sense safety \\
\hline
\end{tabular}


be alone: "Yes, I suppose I am a bit special so I keep to myself, but it's important to be able to choose to feel security". Being alone was about the right to be left on their own and have no obligation to be sociable in meetings with other older persons living in the nursing home.

\section{Interpersonal Security - To Interact with Others}

The older persons interacted with others and adapted to the staff's routines and to other older persons to feel and sense interpersonal security. Realizing that there were others who needed help meant that they were not alone. Reciprocity and feeling they could trust the staff created interpersonal security. There was also a longing or desire for security represented by coherence and affinity to the family and to being liked by the staff.

\section{To Adapt to Others and to the Staff's Routines}

The older persons reflected that there was too few staff in relation to the number of older persons who needed a great deal of help with personal care. The personal care took away from the time the older persons had for receiving help with other things like their eyeglasses, hearing aids and medication. The stories revealed that the older persons saw and heard that the staff were stressed. The staff talked about how much they had to do, as one person reported: "There was somebody [staff] who said, 'Ugh, what a pain it is'". The stress that the staff voiced resulted in the older persons finding it best to learn to adapt to staff routines in order to feel some sort of security. An older person reflected:

We are four or five people on this side, and over here I do not know how many we are ... it is a little bit difficult for me to adapt. There are the entire corridor with people who need help and that is what has surprised me that even though I'm over 90 years, I have a lot to learn, I must learn to be flexible, patient and I may think like this yes but she might be next door with someone else.

The older persons who did not need so much help had to be persevering and patient and remember there were others who needed to receive help before they did. They were told by the staff that they would have help but had to wait for their turn. This resulted in them not asking to have some of their needs met and routines kept.

\section{To Recognizing Oneself in Others}

The older persons reflected that other older persons in the nursing home needed more help than they did themselves, for example, with bathing and dressing. This also meant that others were sicker than themselves and they could partially rely on themselves. They had also noticed that others had a poorer memory than they did. This resulted in a sense of security because they knew they were not alone in needing help. An older person reflected on this by saying: "I don't have so much in my head today ... I have such a bad memory. I lose the names of flowers and names on places, and such. I know-I'm not alone”.

\section{To Sense Reciprocity}

At the same time as the older persons described that they had adapted, they said they felt trust in the staff. They did not experience that they disrupted the staff because the staff were careful to encourage them to ask for help if they needed it: "Security means that you need not feel that you should not disturb [staff]; you never have to feel that". Since the older persons felt that the staff catered to their needs, they did not think they had anything to complain about. One person said: "Then you are calm and happy with things. And I sense security and I have it good here, but not like before; then one could work and do things, but it works anyway". They said that the staff could also trust them because there was reciprocity between themselves and staff. Some of the older person said that staff listened to them and what they had to say. The older persons liked the staff and could have confidential conversations with them and tell them about concerns that weighed on them. The older persons also listened to the staff and their worries: "We trust each other and we can talk about problems and worries, with each other or anything, it provides security".

\section{To Long for Coherence and Affinity}

The older persons said that security in earlier life had been belonging to family, relatives and friends. An older person said: "I do not really know what security is. One had been secure in the family and with relatives, but relatives are so far away". Others said that they missed and longed for what had been their home: "I would like to have my own [home] that I'm used to". They also longed for their family and the security that they represented. When the family came to visit the nursing home, the older persons sensed coherence and togetherness: "Yes it is important. I have a son and daughter-in-law and my husband and they come as often as they can". The older persons reflected that it became difficult to create a sense of friendship and security towards other older persons in the nursing home. Even though they spent their everyday life with other older persons, they found it difficult to establish contacts. One reason was that it could be difficult to communicate when many had impaired hearing. A consequence of this was that no one spoke to the other at the dinner table because they knew they had to shout:

There are five of them sitting at the table and everyone hears badly. There is somebody that I like very much but she cannot hear, I myself hear badly too. So it's a bit boring when you sit and eat and there is no one saying anything.

\section{To Long for to be Liked}

These stories revealed a longing for to be liked of the staff in order to experience security in the nursing home. They said that if the staff cared about those who lived there, instead of sticking to the daily routines such as cleaning, it would be much better. The staff should be kind and sweet and have a personable attitude and like them: "Security for me is to stay here, to be liked as much as possible. Then I feel satisfaction". Some of the older person said they were 
alone; they had no relatives they could feel loved by. The feeling of being alone could be alleviated when they were met with kindness: "I have nobody here, just a couple of girls, [staff]. We can talk about everything. In the evenings, they come with the medicine, and then they sit down". To be seen and be liked by the staff created an interpersonal security.

\section{External Security - To Obtain Protection}

The protection inside the walls of the nursing home constituted an external security. There was help available 24 hours a day and no outsiders could enter unannounced. It was also possible for the older persons to move about freely.

\section{To Sense Safety}

The older persons said that they had moved to a nursing home for security. Safety existed because there were staffs available 24 hours a day from whom the older persons could quickly get help, which meant that they thrived and sense security: "The fact is that I cannot move as I want by myself, so I have security here". It felt good to know that the main entrance was locked during certain times of day. This meant that no external person could enter their apartment. If anyone came in, they could be sure that it was always a staff: "It means of course no one comes in, no one comes and rings the doorbell as they could do in the [ordinary housing]. I did not open [the door] then". Because the front door was locked, they did not need to lock their apartment door behind them, which created a sense of security, because, if for example, they fell down, they could push the alarm, and staff could quickly get in and help them. Some of the older persons also said they felt secure because they could move freely within the property and were able to go out into the landscaped garden.

\section{DISCUSSION}

A qualitative difference and a contradiction are apparent in the results. On one hand, the older persons adapted to their own and others' needs and the staff routines and formed reciprocal relationships and thus created a sense of security. This adaptation and the formation of relationship may mean that the care is institution-centred. On the other hand, they longing to continue to trust themselves and create their own everyday life, have a sense of coherence and affinity (i.e. belonging), and to be liked. This can be linked, to an ontological security, which is emotional and has to do with the phenomenological term of being in the world [8]. It is about having a sense of confidence in the continuity of self-identity [9] and in the continuity and order of events [9]. Further, ontological security is a sense of the reliability of persons and things $[8,9]$. In the care of the older persons, personcentred care can provide the balance of power that allows the older person to obtain ontological security. This happens because person-centred care is based on the older person's values and beliefs about how she or he wants to design her or his everyday life and live her or his life [28].

In this discussion, a weighing scale with two pans is used to illustrate how person-centred care can create a balance of power that enables the older person to obtain ontological security (see Fig. 1). The goal is to tip the balance of power by providing more person-centred care than institutioncentred care and, thereby, provide older persons with ontological security and a being in the world, so they have a continuity of their self-identity instead of a need to adapt to others.

\section{Being with Self}

The older persons said that they had adapted to their increased needs and moved to a nursing home to have a sense of security and to get help quickly. This may mean that the basic needs of the physiological security were met [5]. However, the care can become institution-centred: task-oriented with limited space for psychosocial and communicative aspects, starved of time and little engagement with the older persons [20, 28]. Many older persons are choosing to move to feel secure $[14,15]$, a move that represents a major change in their life [29]. However, there is a risk that they may not feel at home and secure if they do not consider the nursing home as their home [30]. This study revealed that the older persons longed for an ontological security represented by coherence and affinity with their home [ordinary housing] and family and also that they wanted to be liked. Staff can use person-centred care to make the older person feel secure and at home. If the staffs affirm older persons, they will feel recognized, respected, and trusted. Staff also should recognize the values older persons hold about their lives and how they make sense of daily life. This will enable older persons to trust themselves [28, 31]. In person-centred care that considers affirmation of how the older persons wants to be with self and recognitions of her/his values, the balance of power is on the older person's side $[28,31]$. This means that the person will have a sense of confidence in the continuity of self-identity and of order in events and it allows a being in the world $[8,9]$.

The older persons in this study created an inner and interpersonal security when they adapted to their own and the needs of other older persons [14], and to the staff routines $[13,14,20]$. This is in line with Crittenden [7] who says that every person has their own approach for creating a sense of security. Adapting can be a way to gain control, to ensure an external order that provides an internal emotional calm, which in turn creates security [9]. People can adapt in various ways [32], for example, by prioritizing own needs and only choosing those that are most salient to their life [33, 34]. The older person can also change their internal values and adapt to negative circumstances [35]. If person-centred care is missing and the care is institution-centred [20], the older person adapts, giving up her- or himself and becoming resigned to the situation, which can turn into depression and apathy [36].

\section{Being in Place}

To enable the older person to sense a being in the world, person-centred care can be used to change the balance of power. Then it is important to shape the elderly care based on what the older person likes to be in place because it is through the place, or the context, that personhood is articulated $[28,37]$. This will make it easier for older persons to live their life as they have done always, to maintain their routines and habits, in other words, their lifestyle [9]. The 


\section{Institution-centred care}

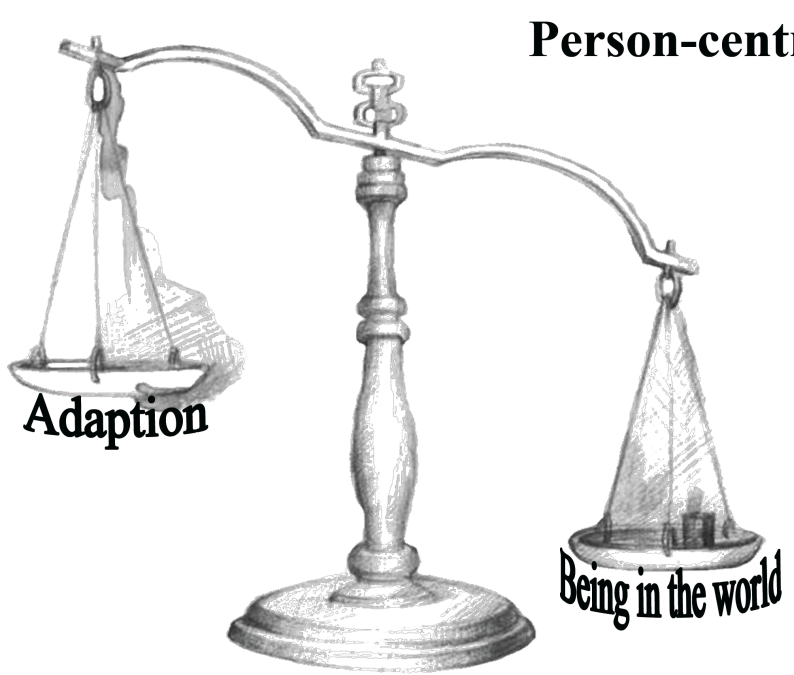

Fig. (1). The balance of power: Illustration of how person-centred instead of institution-centred care can provide the balance of power that allows the older person to obtain a sense of ontological security and a being in the world.

person's needs for protection and a sense of belonging would also be satisfied.

Person-centred care that considers the older persons lifestyle puts the balance of power on the older person's side. This might preserve inner emotional security, and is interpreted here as ontological security $[8,9]$.

\section{Being in Relation}

When the staffs have knowledge of the older person's lifestyle, the conditions are favourable for the development of therapeutic relationships and interventions, which is fundamental in person-centred care. A therapeutic intervention aimed at caring actions results in positive improvements such as physical and mental well-being for the older person. Staff can also experience mental well-being, reduced stress and increased job satisfaction. A therapeutic relationship is built on the sharing of collective knowledge, mutual trust and understanding between staff, the older person and others who are significant to the older persons [28, 38].

In person-centred care that considers a therapeutic relationship, the balance of power is on the older person's side and an ontological security can be obtained.

Furthermore, as this study suggests, the older persons listened to the staff's concerns and the staff listened to the older persons, which created reciprocity and an interpersonal security. However, reciprocity can be problematic; older persons who need health care and social service can struggle between their desire to maintain their independence and their need to have their care needs met and, therefore, having to relate to staff [39] and create reciprocity. Giddens [9] says that a person only senses security in her or his own identity to the extent that others recognize her or his behaviour and find it is appropriate for the situation. This could be interpreted to mean that the older person is not asking to have their needs met in the way that they want. Reciprocity between the older person and the staff could mean that the staff are familiar with the older person's manner of being and the older person is so keen about reciprocity that he or she does not have the courage to step outside her or his usual way of being and ask questions about extended or changing needs. In the long term, this could mean the older person falls into a dependency in which they have to behave as they usually do because it is the only behaviour that is appropriate for the situation. Because of this, there is a risk that they will not receive care or if they do, not in the way they want. Without person-centred care, the older person who has had to adapt might loses ontological security.

In this study, the older persons also said they did not feel that they disturbed the staff and could rely on staff. McGilton and Boscart [40] describe a form of partnership between caregivers and those they cared for that allowed them to together make the everyday work. In Gantert et al. [39], it becomes clear that older persons experienced that it was important to create and develop emotional bonds with their caregivers, which was facilitated when there was reciprocity in the relationship. Reciprocity in person-centred care appears to be the foundation of a good personal relationship. The personal relationship can mean a communication between staff and the older person. In person-centred care that considers being in relation, good personal relationship, the balance of power is on the older person's side, which can contribute to help provide ontological security. A prerequisite for practice in person-centred care is that the staffs have insight about how they themselves act as individuals. They must be aware of how their own values and beliefs affect their own and the older person's decisions [28, 38]. It may be easier for the staff if the older person adapts and this could mean that staffs obtain control, which may result in emotional security for themselves [8] and result in an institutioncentred care. It follows that staff may need to support the older person in not adapting to other older persons in the nursing home or to staff routines. In person-centred care that considers that staff have insights in own values and beliefs, the balance of power is on the older person's side. 
The older persons described a longing to trust themselves, which seems to be central for internal security $[10$, 11]. A sense of mastery is a single source indicator of an individual's sense of security or insecurity, which is dependent on the older person's ability to control and deal with stressful life events. The staff can support older persons in mastering an individual sense of security, if they have knowledge of older person's capacity to handle life events [41]. This knowledge can be obtained through the life biography, which is important in person- centred care. Biographical approaches are not just about "collecting stories" as a part of the assessment but also about the intrinsic worth of a person $[28,42]$. These narratives afford the opportunity to have self-identity reflectively understood by both the individual and by others [9]. The question arises about how the older persons who are totally dependent on help can trust themselves. The older persons in this study said internal security meant being able to ask for the help they needed, to do what they could, and to choose with whom they would spend time. Even Crist [43] reports that independence is not necessarily related to physical ability but to the freedom of making independent decisions. Consequently, it seems that making small decisions can lead to the older person being able to trust her- or himself and influence their own daily life. The challenge for the staff can be that they must allow everyone in the nursing home, even the older persons who are cognitively impaired, to make independent decisions so they can to maintain their autonomy [44]. However, there may be a danger if staffs believe that persons who are cognitively impaired cannot make independent decisions; the ability to make decisions and being cognitively impaired need not be related [45]. Person-centred care requires staff to empower the older person to make their own decisions [46]. The older person's wishes, longings, and desire to make her or his own choices can be satisfied [47] when the staffs support the older person to argue for her or his choices [48]. It is possible to identify someone's choices desire and values through their life biography [49]. Staff should deduce from the person's history who the older person is and what is important to the person. This must always be done in any context since the life biography is under constant development [28]. In person-centred care that considers a life history, the balance of power is on the older persons' side and older persons can sense that they can make their own choices, influence their everyday lives and have events continue, obtain an ontological security and be in the world $[8,9]$.

\section{Being in a Social World}

The older persons longed for interaction with others, an interpersonal security in which they were liked by the staff. Relationships with the staff were described as important for security [21] and being able to create a sense of belonging and value [47]. When the staff listened to older persons, affirmed them as individuals, and gave them enough time, the older persons could feel valued as human beings [50]. In order to create a relationship with an older person, the staff may need to use engagement and emotional closeness in person-centred care [28] so the person feels appreciated. Emotional engagement can promote a sense of security in another and emotional knowing is valuable in interpersonal relationships [51]. When staffs use emotional knowing in nursing practice, it can create a safe, secure milieu for older persons, as in this study [52]. In person-centred care that considers emotional knowing, the balance of power is on the older person's side. The older person can sense a constancy of the surrounding social and material environments and their ontological security is strengthened [8].

The older persons longed to belong to home and family. The family in itself can mean safety and security [53], a place where the older person may have had an important role as someone who had answers to difficult questions and was someone to trust. When an elderly family member lives in a nursing home, patterns change within the family. There may be difficulties for the rest of the family who may avoid visiting the older person because they feel it is emotionally painful. They can consider the nursing home as a waiting house for death with an institution- centred care [20]. When a family member or a next of kin to someone has deteriorating health, this will also affect the others/family members. This happens because people are included in each other's lives and need each other. Therefore, in providing care it is important for the staff to include the older person's family members and next of kin so the whole family is in the centre and family members can give each other emotional closeness and affinity [53]. The family should be viewed as a unit [53]; having emotional closeness to and social support from significant others is important for a sense of security $[10,13]$. It is important that staff be inviting and collaborate with family because staff's being interconnected with the older person's being in a social world $[28,37]$ can give the older person a sense of belonging to others. Person-centred care that considers the older persons family puts the balance of power on the older person's side which can allow them an ontological security, a being in the world $[8,9]$.

\section{Methodological Considerations}

To achieve credibility in the study, the authors have continually discussed and reflected together. The result contains direct quotations, which gives the reader an opportunity to judge credibility. Because several of the older persons had difficulties in expressing themselves due to illness, the referenced quotations do not always do justice to the meanings that emerged throughout the interviews. This can mean that a particular interpretation of the manifest part of the content analysis could have taken place during the conversation, which can be regarded as a weakness and may affect the study's credibility. On the other hand the interviewer had long experiences from working with older persons with dementia and cognitive impairments. Due to that she could judge if the older person's statements were credible. The interviews produced stories about the manifest content of what security could be or not could be and about conditions that inhibited security. In an interview in which the focus is on what a good life is or what good is, a researcher may indirectly shed light on the matter by talking about what is missing or what is at stake [54]. In each interview, the same opening question was asked about security, which strengthens creditability [27]. The number of older persons who took part could be considered small. According to Sandelowski [55], the sample size in qualitative research should be large enough to achieve a variation of experiences and small 
enough to permit a deep analysis of the data. A strength, however, could be the repeated interviews.

\section{CONCLUSION}

The results in this study showed that to feel secure, the older persons adapted to their own and others' needs and to staff routines. They trusted the staff but also longed to trust themselves, and of being liked and have a sense of continuity and order in events. Then they could maintain their selfidentity and have a sense of belonging. This can be interpreted as an ontological security and linked to a being in the world. The four concepts described by McCormack and McCane [28] as a part of person-centred care can be used as guidelines to develop and ensure delivery of person-centred care and in doing so create ontological security for the older person. If the staffs support the older persons' being with self and the values the older persons hold about their lives and how they make sense of daily life can enable older persons to trust themselves. Further, it is through being in relation that the staffs create reciprocity, reliability, and emotional connection so the older persons feel they belong and are liked. In being interconnected with the older persons' being in a social world [28, 37], staff can give the older person a sense of belonging to others. By shaping the elderly care based on what the older person think about being in place, the person's needs for protection $[28,37]$ and a sense of belonging can be satisfied. Person-centred care can provide the balance of power that allows the older person to obtain, ontological security, a being in the world; the staff's ability to create a relationship with the older persons becomes crucial in providing person-centred care [9].

\section{AUTHOR CONTRIBUTIONS}

Study design: IJ, AK. Data collection: RAM; and analysis: IJ, RAM, AK. Manuscript preparation: IJ, RAM, AK.

\section{CONFLICT OF INTEREST}

The authors confirm that this article content has no conflict of interest.

\section{ACKNOWLEDGEMENTS}

We are grateful for the participation of the older persons in the study. This study was supported by grants from Örebro University Sweden and Länsförsäkringar, AB, Stockholm, Sweden.

\section{REFERENCES}

[1] World Health Organisation. Ageing and life course: interesting facts about ageing. World Health Organization: 2012 March 28; [cited 2013-11-05]. Available from: http://www.who.int/ageing/a bout/facts/en/

[2] Swedish Ministry of Health and Social Affairs. Lagrådsremiss: värdigt liv i äldreomsorgen. [The council of legislation remittance: dignity life in elderly care]. 2010; [cited 2013-11-05]. Available from: http://www.regeringen.se/sb/d/108/a/138285 (in Swedish).

[3] SFS. 2001:453 Socialtjänstlagen. [The Social Service Act]. Swedish Ministry of Health and Social Affairs; [cited 2013-11-05]. Available from: http://www.riksdagen.se/sv/Dokument-Lagar/Laga $\mathrm{r} /$ Svenskforfattningssamling/Socialtjanstlag-2001453 sfs-2001- (in Swedish).
[4] Kaufmann F-X. Norms and institutions as means of coping with insecurity: the sociological perspective. In: Holzheu F, Ed. Society and uncertainty. Karlsruhe: VVW 1987; pp. 37-48.

[5] Maslow AH. A theory of human motivation. Psychol Rev 1943; 50(4): 370-96.

[6] Bowlby J. Psychoanalysis as a natural science. Psychoanal Psychol 1984; 1(1): 7-21.

[7] Crittenden PM. Danger and development: the organization of selfprotective strategies. Monogr Soc Rws Child 1999; 64(3):145-71.

[8] Giddens A. The consequences of modernity. Stanford, Calif: Standford University Press 1990.

[9] Giddens A. Modernity and self-identity: self and society in the late modern age. Cambridge: Polity press 1991.

[10] Petersson P, Blomqvist K. Sense of security - searching for its meaning by using stories: a participatory action research study in health and social care in Sweden. Int J Older People Nurs 2011; 6(1): 25-32.

[11] Burström M, Brännström M, Boman K, Strandberg G. Life experiences of security and insecurity among women with chronic heart failure. J Adv Nurs 2012; 68(4): 816-25.

[12] DeWitt L, Ploeg J, Black M. Living on the threshold: the spatial experience of living alone with dementia. Dementia 2009; 8(2): 263-91.

[13] From I, Johansson I, Athlin E. Experiences of health and wellbeing, a question of adjustment and compensation - views of older people dependent on community care. Int J Older People Nurs 2007; 2(4): 27887.

[14] Hjaltadóttir I, Gústafsdóttir M. Quality of life in nursing homes: perception of physically frail elderly residents. Scand J Caring Sci 2007; 21(1): 48-55.

[15] Andersson I, Pettersson E, Sidenvall B. Daily life after moving into a care home- experiences from older people relatives and contact persons. J Clin Nurs 2007; 16(9): 1712-8.

[16] Tsai HH, Tsai YF. A temporary home to nurture health: lived experiences of older nursing home residents in Taiwan. J Clin Nurs 2008; 17(14): 1915-22

[17] Bergland $\AA$, Kirkevold M. Thriving in nursing homes in Norway: contributing aspects described by residents. Int J Nurs Stud 2006; 43: 681-91

[18] Shin JH, Park T, Huh IS. Nursing staffing and quality of life in western New York nursing homes. West J Nurs 2013; 36(6): 788805.

[19] Timonen V, O'Dwyer C. Living in institutional care: residents' experiences and coping strategies. Soc Work Health Care 2009; 48(6): 597-613.

[20] Tuckett AG. The meaning of nursing-home: 'Waiting to go up to St. Peter OK! Waiting house sad but true'- an Australian perspective. J Aging Stud 2007; 21(2): 119-33.

[21] From I, Johansson I, Athlin E. The meaning of good and bad care in the community care: older people's lived experiences. Int J Older People Nurs 2009; 4(3): 156-65.

[22] James I, Blomberg K, Liljekvist E, Kihlgren A. Working together for a meaningful daily life for older persons - a participatory and appreciative action and reflection project: the lesson we learned. Submitted 2014.

[23] Örebro kommun: Brukarundersökning särskilda boenden och hemvården. Örebro Municipality:user survey nursing home and home care. Social welfare] 2010; [cited 2013-11-05]. Available from: http://www.orebro.se/download/18.47c6f44f12dd9e9713780 002115/1392724621772/S\%C3\%A4rskilda+boenden+f\%C3\%B6r+ $\% \mathrm{C} 3 \%$ A4ldre, +deras + anh $\% \mathrm{C} 3 \% \mathrm{~B} 6$ riga + och + hemv $\% \mathrm{C} 3 \% \mathrm{~A} 5 \mathrm{rden}+$ hela+unders\%C3\%B6kningen+-+brukarunders\%C3\%B6kning+2010. pdf (in Swedish)

[24] Szala-Meneok K. Ethical research with older adults. In: Mertens DM, Ginsberg PE, Eds. The handbook of social research. Thousand Oak: CA: Sage Publications Inc. 2009; pp. 507-17.

[25] DiCicco-Bloom B, Crabtree BF. The qualitative research interview. Med Educ 2006; 40(4): 314-21.

[26] Schön DA. The reflective practitioner: how professionals think in action. Repr. [= New ed.]. Aldershot Aena: 2003; [1995].

[27] Graneheim UH, Lundman B. Qualitative content analysis in nursing research: concepts, procedures and measures to achieve trustworthiness. Nurse Educ Today 2004; 24(2): 105-12.

[28] McCormack B, McCane T. Person-centred nursing. Theory and practice. Chichester: John Wiley \& Sons Ltd; 2010. 
[29] Anderberg P, Berglund AL. Elderly persons' experiences of striving to receive care on their own terms in nursing homes. Int J Nurs Pract 2010; 16(1): 64-8.

[30] Saino J, Hansebo G. Moving to a nursing home- a new phase in life an interview study. Nurs Sci Res Nord Ctries 2008; 28: 27-31. (in Swedish).

[31] McCormack B, Karlsson B, Dewing J, Lerdal A. Exploring personcentredness: a qualitative meta-synthesis of four studies. Scand J Caring Sci 2010; 24(3): 620-34.

[32] Aminzadeh F, Dalziel WB, Molnar FJ, Garcia LJ. Symbolic meaning of relocation to a residential care facility for persons with dementia. Aging Ment Health 2009; 13(3): 487-96.

[33] Dunér A, Nordström M. Intentions and strategies among elderly people: coping in everyday life. J Aging Stud 2005; 19(4): 437-51.

[34] Lazarus RS. Emotions and interpersonal relationships: toward a person-centred conceptualization of emotions and coping. J Pers 2006; 74(1): 9-46.

[35] Sprangers MA, Schwartz CE. Integrating response shift into healthrelated quality of life research: a theoretical model. Soc Sci Med 1999; 48(11):1507-15.

[36] Mellor D, Davison T, McCabe M, George K. Professional carers' knowledge and response to depression among their aged-care clients: the care recipients' perspective. Aging Ment Health 2008; 12(3): 389-99.

[37] McCance T, McCormack B, Dewing J. An Exploration of personcentredness in practice. Online J Issues Nurs 2011; 16(2): 1.

[38] McCormack B. Person-centredness in gerontological nursing: an overview of the literature. J Clin Nurs 2004; 13(Supplement s1): 31-8.

[39] Gantert TW, McWilliam CL, Ward-Griffin C, Allen NJ. The key to me: seniors' perceptions of relationship-building with in-home service providers. Can J Aging 2008; 27(1): 23-34

[40] McGilton KS, Boscart VM. Close care provider-resident relationships in long-term care environments. J Clin Nurs 2007; 16(11): 2149-57.

[41] Fagerström L, GustafsonY, Jakobsson G, Johansson S, Vartiainen P. Sense of security among people aged 65 and 75 : external and inner sources of security. J Adv Nurs 2011; 67(6): 1305-16.
[42] Ford P, McCormack B. Future directions for gerontology: a nursing perspective. Nurse Educ Today 2000; 20(5): 389-94.

[43] Crist JD. The meaning for elders of receiving family care. J Adv Nurs 2005; 49(5): 485-93.

[44] Kane RA. Long-term care and a good quality of Life: bringing them closer together. Gerontologist 2001; 41(3): 293-304.

[45] UCLA OHRPP: office of the human research program: guidance and procedure: research involving persons with cognitive impairments. (last updated May 24, 2013) ; [cited 2013-12-05]. Available from: http://ora.research.ucla.edu/OHRPP/Documents/Policy/9/Co gnitive Impairments.pdf

[46] Slater $\overline{\mathrm{P}}$, McCormack B, Bunting B. The development and pilot testing of an instrument to measure nurses' working environment: the Nursing Context Index. Worldviews Evid Based Nurs 2009; 6(3): 173-82.

[47] Frankfurt HG. Freedom of the will and the concept of a person. J Philos 1971; 68(1): 5-20.

[48] Slettebø Å. Empowerment in nursing homes: lessons for district nursing? Br J Community Nurs 2006; 11(3): 115-8.

[49] McCormack B. A conceptual framework for person-centred practice with older people. Int J Nurs Pract 2003; 9(3): 202-9.

[50] Woolhead G, Tadd W, Boix-Ferrer JA, et al. "Tu" or "Vous?" A european qualitative study of dignity and communication with older people in health and social care settings. Patient Educ Couns 2006; 61(3): 363-71.

[51] McQueen ACH. Emotional intelligence in nursing work. J Adv Nurs 2004; 47(1): 101-8.

[52] James I, Andershed B, Gustavsson B, Ternestedt BM. Emotional knowing in nursing practice: in the encounter between life and death. Int J Qual Stud Health Well-being 2010; 5(2): 1-15.

[53] Wright LM, Leahey M. Nurses and families: a guide to family assessment and intervention. $6^{\text {th }}$ ed. Philadelphia: F.A. Davis; 2013.

[54] Løgstrup KE. System og symbol: essays. $2^{\text {nd }}$ ed. København: Gyldendal 1997.

[55] Sandelowski M. Sample size in qualitative research. Res Nurs Health 1995; 18(2): 179-83. 